\title{
First-generation antipsychotic long-acting injections $v$. oral antipsychotics in schizophrenia: systematic review of randomised controlled trials and observational studies
}

Peter M. Haddad, Mark Taylor and Omair S. Niaz

\section{Background}

Antipsychotic long-acting injections (LAIs) are often used in an attempt to improve medication adherence in people with schizophrenia.

\section{Aims}

To compare first-generation antipsychotic long-acting injections (FGA-LAIS) with first- and second-generation oral antipsychotics in terms of clinical outcome.

\section{Method}

Systematic literature review.

\section{Results}

A meta-analysis of randomised controlled trials (RCTs) showed no difference in relapse or tolerability between oral antipsychotics and FGA-LAls but global improvement was twice as likely with FGA-LAls. Four prospective observational studies were identified; two studies reported lower discontinuation rates for FGA-LAls compared with oral medication and two found that outcome was either no different or better with oral antipsychotics. Mirror-image studies consistently showed reduced in-patient days and admissions following a switch from oral antipsychotics to FGA-LAls.

\section{Conclusions}

The results are variable and inconclusive. Some evidence suggests that FGA-LAls may improve outcome compared with oral antipsychotics. Methodological issues may partly explain the variable results. Selective recruitment in RCTS and lack of randomisation in observational studies are biases against LAls, whereas regression to the mean in mirrorimage studies favours LAls. In terms of future research, a long-term pragmatic RCT of an FGA-LAl against an oral antipsychotic, in patients with problematic adherence, would be of value.

\section{Declaration of interest}

P.M.H. and M.T. have received fees for lecturing and consultancy from the manufacturers of various antipsychotics, including AstraZeneca, Bristol-Myers Squibb, Eli Lilly and Janssen-Cilag.
First-generation antipsychotic long-acting injections (FGA-LAIs) were introduced in the $1960 \mathrm{~s},{ }^{1}$ and continue to be widely used today in both the $\mathrm{USA}^{2}$ and the $\mathrm{UK}^{3,4}$ for the maintenance treatment of schizophrenia. In meta-analyses antipsychotics are superior to placebo in reducing relapse in schizophrenia, ${ }^{5}$ and randomised studies have shown that continuous maintenance medication is associated with lower relapse rates than intermittent targeted medication given only when there are early warning signs of a possible relapse. ${ }^{6,7}$ In practice the effectiveness of maintenance antipsychotic treatment is often undermined by poor adherence, with Cramer \& Rosenheck estimating a medication adherence rate in schizophrenia of $58 \% .^{8}$ Stopping antipsychotic medication is a common cause of relapse, ${ }^{9}$ and even a 10 -day period of missed medication has been associated with an increased risk of readmission due to relapse. ${ }^{10}$ Partial adherence may lead to poor symptom control irrespective of an increased risk of relapse, so by improving medication adherence LAIs may reduce relapse and improve symptom control. The regular contact with nursing staff that accompanies LAI treatment may have further benefits. An important proviso is that this argument assumes that those who adhere poorly to a regimen of tablets will accept an injection. Some patients will not, and so LAIs are not a panacea for adherence problems nor are they the only strategy by which to improve adherence.

In summary, there are intuitive reasons why LAIs may improve clinical outcomes but the key issue is whether evidence supports this. In this article we systematically review studies that compare the effectiveness of FGA-LAIs with both first- and second-generation antipsychotic oral medication in schizophrenia.
First-generation antipsychotic LAIs are used in other disorders, including bipolar disorder, ${ }^{11}$ but this is less frequent and outside the remit of this review. We have reviewed both randomised controlled studies and observational studies as they assess different outcomes. Randomised controlled trials (RCTs) assess efficacy, i.e. does a drug lead to benefit in ideal circumstances. Observational studies assess effectiveness, i.e. does a drug have benefit in the real world where dose, patient characteristics and follow-up may be more variable than in an RCT.

\section{Method}

\section{Search strategy}

A systematic search of the MEDLINE, EMBASE and PsycINFO databases was conducted in September 2008 using the terms antipsychotic, depot and long-acting injection, and mapping to $\mathrm{MeSH}$ terms, with the limits humans, adults, clinical trial, metaanalysis, randomised controlled trial, comparative study, English. There were no limitations by date. Abstracts of articles were reviewed against our inclusion and exclusion criteria. The references cited by included studies were reviewed for additional relevant cited articles, and the citation search facility was employed to identify further potentially relevant original studies.

\section{Inclusion and exclusion criteria}

For inclusion, studies were required to:

(a) include a group of patients treated with an FGA-LAI; 
(b) include an oral antipsychotic comparator (first- or secondgeneration);

(c) provide original quantitative data on efficacy or effectiveness;

(d) (for RCTs and prospective observational studies) be restricted to those that recruited patients with schizophrenia, schizoaffective disorder or schizophreniform disorders.

The last inclusion criterion was not applied to retrospective studies as these frequently reported on the outcome of a cohort of patients treated with LAIs irrespective of diagnosis. No specific quality threshold was set for inclusion of studies. Studies were excluded if there were fewer than 20 patients in the LAI arm, if no original patient data were reported (e.g. 'modelling' studies) or if the comparator group was given a placebo, another FGA-LAI or risperidone LAI.

\section{Statistical analysis}

Included studies were divided into four groups: RCTs, prospective observational studies, mirror-image studies and other retrospective observational studies. Quantitative data were extracted. In some mirror-image studies admission and in-patient data were presented only in graph form in the original articles and/ or $P$-values were not given. Where possible we have extrapolated the missing data and calculated $P$-values using data from the original publications. The summary table for mirror-image studies (see Table 2) indicates where secondary calculations have been made. No further statistical analysis was applied.

\section{Results}

\section{Search strategy}

The initial search strategy revealed 249 potentially relevant study abstracts, which were individually scrutinised against the inclusion criteria. Seven further possible studies were identified through citation search. After inclusion and exclusion criteria were applied, the remaining studies were categorised as RCTs ( 1 meta-analysis that considered FGA-LAIs as a total group and 1 RCT); prospective observational studies (4 studies); mirror-image studies (11 studies); other retrospective observational studies (2 studies).

The one meta-analysis of FGA-LAIs $v$. oral medication that we identified was part of a comprehensive systematic meta-review of LAIs by Adams et al. ${ }^{12}$ This review was based on a synthesis of data from eight Cochrane reviews of individual FGA-LAIs in patients with schizophrenia or schizophrenia-like illnesses. Since the Adams review was published, five of the Cochrane FGA-LAI reviews on which it was based have been updated. ${ }^{13-17}$ These updates either contain no data comparing LAIs with oral medication or show no significant difference in efficacy between oral and LAI. Consequently the updated Cochrane reviews give no reason to doubt a key result of the meta-analysis by Adams et al, namely that relapse rates do not differ between LAI and oral medication. ${ }^{12}$ In view of this the individual updated Cochrane reviews are not detailed further in this paper.

\section{Randomised controlled trials}

The meta-analysis by Adams et al of FGA-LAIs $v$. oral antipsychotics provided data on several outcomes, including relapse (Fig. 1). ${ }^{12}$ The relapse data are based on a total sample of 848 patients randomised to an FGA-LAI (fluphenazine decanoate, fluspirilene decanoate, pipotiazine palmitate) or an FGA-oral medication (including chlorpromazine, haloperidol, penfluridol and trifluoperazine) (Fig. 1). The duration of included trials varied ( 4 weeks to 2 years), but most patients took part in trials of at least a year in duration. The risk of relapse did not differ between the two groups $(\mathrm{RR}=0.96,95 \% \mathrm{CI} 0.8-1.1)$. In an analysis of 127 patients treated with three FGA-LAIs (fluphenazine decanoate, fluphenazine enanthate and haloperidol decanoate), global improvement (assessed using the Clinical Global Impressions scale) was more likely with FGA-LAI than with FGA-oral medication, with a number needed to treat (NNT) of 4 (95\% CI 2-9). The FGA-LAI and FGA-oral groups were similar in terms of study attrition, the need for adjunctive anticholinergic medication and incidence of tardive dyskinesia (Fig. 1). Anticholinergic medication, a proxy marker for the presence of extrapyramidal symptoms, was prescribed to $69 \%$ of the FGALAI cohort and $65 \%$ of the FGA-oral cohort. The prevalence of tardive dyskinesia in the FGA-LAI cohort was $9.0 \%$ and in the FGA-oral cohort it was $14.1 \%$.

We identified one RCT not included in the original or updated Cochrane reviews of FGA-LAIs, namely that by Arango et al. ${ }^{18}$ This small RCT compared oral zuclopenthixol $(n=20)$ with zuclopenthixol decanoate $(n=26)$ over 1 year in patients with schizophrenia and a history of violence. A lower frequency of violent acts was seen in the LAI group but end-point scores on the Positive and Negative Syndrome Scale (PANSS) did not differ.

\section{Prospective observational studies}

We identified four prospective observational studies that compared an FGA-LAI with one or more oral antipsychotic cohorts (Table 1). ${ }^{19-23}$ These studies had various pragmatic outcome measures, including risk of readmission and time to all-cause discontinuation of medication. Results were mixed. Two studies found a better outcome for FGA-LAI compared with an FGA-oral. ${ }^{19,20}$ The Schizophrenia Outpatient Health Outcomes (SOHO) study found poorer outcomes for FGA-LAI than oral olanzapine, ${ }^{21,22}$ and a fourth study found oral antipsychotics to be superior to haloperidol decanoate but equivalent to fluphenazine decanoate. ${ }^{23}$

Tiihonen et al assessed the outcome of patients after their first admission with schizophrenia or schizoaffective disorder. ${ }^{19}$ The other studies in Table 1 had samples wholly or largely comprising patients who had had schizophrenia for several years. The Tiihonen study assessed a nationwide cohort, all first admissions in Finland occurring over a 51/2-year period, and had a mean follow-up period of 3.6 years. Analysis was performed on the ten most commonly used antipsychotics, which included one injectable formulation: perphenazine LAI. Multivariate models and propensity score methods were used to adjust estimates of effectiveness, and comparisons were made with oral haloperidol. Initial use of perphenazine LAI was associated with a significantly lower adjusted risk of all-cause discontinuation than that for haloperidol and the second lowest discontinuation rate of the ten drugs studied. In an analysis of rehospitalisation rates, calculated according to the ongoing antipsychotic, perphenazine LAI had the lowest risk of rehospitalisation $(68 \%$ reduction in fully adjusted relative risk compared with haloperidol) (Fig. 2). Oral perphenazine showed no difference from oral haloperidol in terms of adjusted risk of discontinuation and rehospitalisation, suggesting that it was the mode of administration rather than the drug per se that was responsible for the improved outcome with perphenazine LAI. ${ }^{24}$

Zhu et al used data from the US Schizophrenia Care and Assessment Program (US-SCAP) study to assess the time to allcause medication discontinuation in the first year after initiation of an FGA-LAI or oral antipsychotic. ${ }^{20}$ The study assessed the same two antipsychotics - haloperidol and fluphenazine - in oral or LAI form. Compared with those treated with oral medication, 


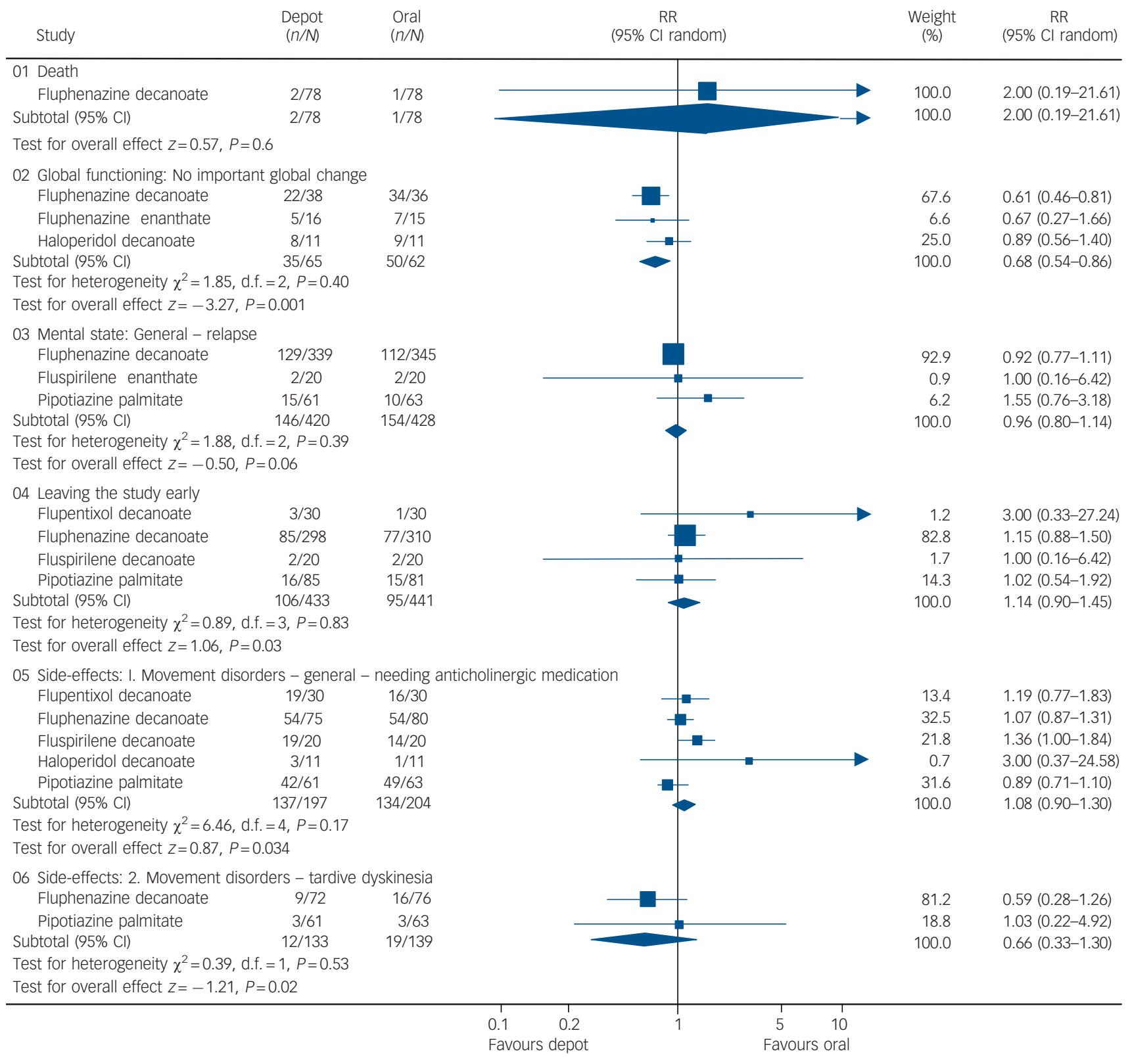

Fig. 1 Outcomes for antipsychotic treatment: long-acting injection (LAI) v. oral. From Adams et al, ${ }_{1}^{12}$ reproduced with permission.

those treated with LAI had a significantly longer mean time to allcause medication discontinuation and were twice as likely to continue taking the medication (Fig. 3).

The SOHO study was a pan-European observational study funded by Eli Lilly that recruited over 10000 patients with schizophrenia when they began a new antipsychotic medication regimen on an out-patient basis. $^{21}$ Patients were assessed at regular intervals for up to 3 years or until discontinuation of the baseline antipsychotic. The study included various SGA-oral cohorts plus a mixed cohort prescribed various FGA-LAIs and another mixed cohort taking various FGA-orals. Statistical comparisons were made relative to oral olanzapine. The likelihood of not achieving remission, the risk of relapse and the all-cause discontinuation rate of medication were all higher for those treated with FGA-LAI compared with oral olanzapine. ${ }^{21,22}$ The proportion of individuals who had stopped medication by 3 years was $36.4 \%$ for those taking olanzapine, $50.2 \%$ for those who began FGA-LAI treatment and $53.1 \%$ for those taking an oral FGA. ${ }^{22}$ The hazard ratio (risk) for discontinuation relative to olanzapine for FGA-orals was 1.70 (95\% CI 1.46-1.97) and for FGA-LAIs it was 1.43 (95\% CI $1.19-1.70){ }^{22}$

Conley et al assessed the risk of readmission in patients discharged from several in-patient psychiatric units in the State of Maryland, USA. ${ }^{23}$ Cohorts discharged on fluphenazine decanoate and haloperidol decanoate were compared with cohorts discharged on one of three SGA-orals. The 1-year readmission risk (with adjustment for baseline variables) for each of the three SGA-oral groups was lower than for the haloperidol decanoate group but similar to that seen with fluphenazine decanoate.

The only study in Table 1 that presented tolerability data was the SOHO study, albeit descriptive data without statistical analysis. ${ }^{22}$ The presence of extrapyramidal symptoms and tardive dyskinesia was based on clinical judgement rather than rating scales. The period prevalence for extrapyramidal symptoms 


\begin{tabular}{|c|c|c|c|c|c|c|}
\hline & Country & $\begin{array}{l}\text { Selection } \\
\text { of participants }\end{array}$ & $\begin{array}{l}\text { Follow-up } \\
\text { period }\end{array}$ & LAl group & $\begin{array}{l}\text { Oral } \\
\text { comparator groups }\end{array}$ & Main outcome ${ }^{b}$ \\
\hline $\begin{array}{l}\text { Conley et al } \\
(2003)^{23}\end{array}$ & USA & $\begin{array}{l}\text { Patients discharged } \\
\text { from in-patient care on } \\
\text { LAl or oral medication }\end{array}$ & 1 year & $\begin{array}{l}\text { Fluphenazine } \\
\text { decanoate }(n=59) \\
\text { and haloperidol } \\
\text { decanoate }(n=59)\end{array}$ & $\begin{array}{l}\text { Clozapine }(n=41) \\
\text { risperidone }(n=149), \\
\text { olanzapine }(n=103)\end{array}$ & $\begin{array}{l}\text { One-year risk of readmission for each } \\
\text { oral antipsychotic was lower than for } \\
\text { haloperidol decanoate but not signifi- } \\
\text { cantly different from fluphenazine } \\
\text { decanoate }\end{array}$ \\
\hline $\begin{array}{l}\text { SOHO study } \\
\text { (Haro et al } \\
2006, \\
2007)^{21,22}\end{array}$ & $\begin{array}{l}10 \text { European } \\
\text { countries }\end{array}$ & $\begin{array}{l}\text { Patients who switched } \\
\text { antipsychotic on out- } \\
\text { patient basis }\end{array}$ & 3 years & $\begin{array}{l}\text { Various FGA-LAls } \\
\text { ( } n=348 \text { at baseline) }\end{array}$ & $\begin{array}{l}\text { Conventional cohort and } \\
\text { various atypical cohorts. } \\
\text { Statistical analysis limited } \\
\text { to comparing other } \\
\text { cohorts, including the } \\
\text { LAl cohort, with the } \\
\text { olanzapine cohort } \\
\text { ( } n=4247 \text { at baseline) }\end{array}$ & $\begin{array}{l}\text { 1. Compared with olanzapine, LAls } \\
\text { associated with lower odds ratio of } \\
\text { achieving remission, higher odds ratio } \\
\text { of relapse, and higher rate of all-cause } \\
\text { discontinuation of medication. } \\
\text { 2. Outcome measures given above } \\
\text { similar for oral conventional and LAl } \\
\text { cohorts ( } P \text {-values not provided) }\end{array}$ \\
\hline $\begin{array}{l}\text { Tiihonen } \\
\text { et al } \\
(2006)^{19}\end{array}$ & Finland & $\begin{array}{l}\text { Consecutive patients } \\
\text { discharged after first } \\
\text { admission }\end{array}$ & $\begin{array}{l}\text { Mean } 3.6 \\
\text { years }\end{array}$ & $\begin{array}{l}\text { Perphenazine LAI } \\
\text { (187 person-years } \\
\text { of follow-up) }\end{array}$ & $\begin{array}{l}\text { Various antipsychotic } \\
\text { cohorts. Statistical } \\
\text { comparison with oral } \\
\text { haloperidol } \\
\text { (107 person-years } \\
\text { of follow-up) }\end{array}$ & $\begin{array}{l}\text { Compared with oral haloperidol, } \\
\text { perphenazine LAI was associated } \\
\text { with lower relative risks of both } \\
\text { rehospitalisation and all-cause } \\
\text { discontinuation of treatment }\end{array}$ \\
\hline $\begin{array}{l}\text { US-SCAP } \\
(\text { Zhu et al, } \\
2008)^{20}\end{array}$ & USA & $\begin{array}{l}\text { Patients starting oral } \\
\text { or LAl haloperidol } \\
\text { or fluphenazine }\end{array}$ & 1 year & $\begin{array}{l}\text { Haloperidol } \\
\text { decanoate }(n=47) \\
\text { or fluphenazine } \\
\text { decanoate }(n=50)\end{array}$ & $\begin{array}{l}\text { Haloperidol }(n=109) \\
\text { or fluphenazine }(n=93)\end{array}$ & $\begin{array}{l}\text { Compared with oral medication, those } \\
\text { treated with LAl had longer mean time } \\
\text { to all-cause discontinuation of } \\
\text { medication and were twice as likely to } \\
\text { stay on medication }\end{array}$ \\
\hline
\end{tabular}

(present at any time during follow-up or until medication discontinuation) was $42.8 \%$ for the FGA-LAI cohort and $31.4 \%$ for the FGA-oral cohort, and within the various SGA-oral cohorts values ranged from $13.4 \%$ (quetiapine) to $32.2 \%$ (risperidone). The prevalence of tardive dyskinesia was $12.9 \%$ for the FGALAI cohort and $8.7 \%$ for the FGA-oral cohort, and within the SGA-oral cohorts values ranged from $5.9 \%$ (olanzapine) to $9.8 \%$ (amisulpride). ${ }^{22}$ The proportion of patients who gained more than $7 \%$ in weight from baseline to medication discontinuation was higher for FGA-LAI than for FGA-oral $(21.8 \% v$. 15.7\%), as was mean weight gain $(2.6 \mathrm{~kg} v .1 .5 \mathrm{~kg}) .^{22}$

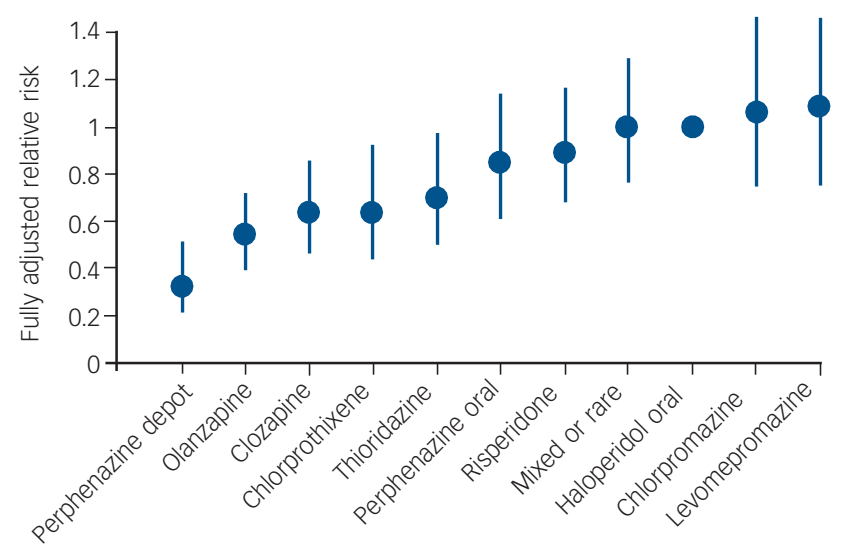

Fig. 2 Risk of rehospitalisation associated with current ongoing antipsychotic compared with oral haloperidol.

Vertical bars indicate $95 \%$ confidence intervals. Adjusted for gender, calendar year, age at onset of follow-up, number of previous relapses, duration of first hospitalisation, and length of follow-up by a multivariate regression and the propensity score method. From Tiihonen et al. ${ }^{19}$ Adapted by permission from BMJ Publishing Group (๑ 2006).

\section{Mirror-image studies}

Mirror-image studies are a specific type of retrospective observational study in which a cohort of patients receiving LAIs is identified and the total number of in-patient days or admissions during LAI treatment is compared with that during an equal time period immediately preceding LAI initiation. For each patient, the duration of treatment on LAI and the duration of the preceding period are the same, i.e. each patient acts as their own comparator. Our search identified eleven mirror-image FGA-LAI studies. ${ }^{25-35}$ In each study, total in-patient days and number of admissions were lower on FGA-LAI than during the preceding treatment period, and where $P$-values were available or could be calculated the differences were statistically significant (Table 2, Fig. 4). Based on the 10 studies with specific in-patient data, the mean number of in-patient days per patient fell from 114.9 in the pre-FGA-LAI period to 28.6 during FGA-LAI treatment (Table 2).

\section{Other retrospective observational studies}

We identified two retrospective observational studies that compared two different patient cohorts, one treated with an FGA-LAI and one with oral medication (Table 3). ${ }^{32,36}$ The readmission rate was lower in the FGA-LAI group in one study, ${ }^{32}$ but did not differ between LAI and oral medication in the other. ${ }^{36}$ One of the two studies provided tolerability data. ${ }^{36}$ Baseline anticholinergic drug use was similar, but during the subsequent 2 years anticholinergic drugs were prescribed more frequently to the patients given injections than to those prescribed an oral drug $(47 \% v .13 \%, P=0.01)$.

\section{Discussion}

\section{Randomised controlled trials}

Adams et al interpreted the equivalent relapse rates and tolerability of LAIs and oral medication in their meta-review (see Fig. 1) as 


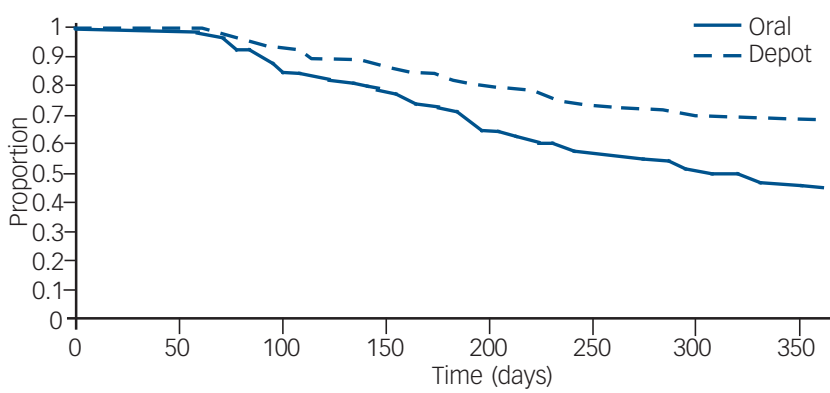

Fig. 3 Survival analysis of time to discontinuation for any reason of first-generation antipsychotics (injected or oral) in the first year after medication initiation. From Zhu et al. ${ }^{20}$ Reprinted with permission from Psychiatric Services (๑ 2008). American Psychiatric Association.

indicating that FGA-LAIs were well tolerated and effective. ${ }^{12}$ The lack of difference in relapse rates is a robust finding given the large sample $(n=848)$, the narrow confidence interval and the fact that most included studies had a duration in excess of 1 year. However, RCTs are likely to selectively recruit adherent patients, resulting in a bias towards finding no difference between the oral and LAI arms. For example, RCTs often exclude patients with comorbid substance misuse, which is strongly associated with poor adherence. ${ }^{37,38}$ Adams et al acknowledged this bias, commenting: 'Those for whom depots (LAIs) are most indicated may not be represented. ${ }^{12}$ Furthermore, in double-blind trials of long-acting injections $v$. oral medication, the oral treatment group receive placebo injections in addition to active oral medication to preserve study masking. ${ }^{39}$ The placebo injection and associated regular staff contact are both absent in the usual care of patients taking oral medication and may enhance the outcome of the oral cohort.

Adams et al found that global clinical improvement was twice as likely in the FGA-LAI group than in the FGA-oral group (see Fig. 1). ${ }^{12}$ This may reflect partial adherence to oral medication, i.e. the rate of non-adherence with oral medication was not high enough for the oral group to show a higher relapse rate than the LAI group (as might have been expected) but was sufficient to undermine symptom control.

\section{Prospective observational studies}

Observational studies have several advantages over RCTs in that they include 'real world' patients, can assess large populations, have long follow-up periods and clinically relevant outcome measures and are financially cheaper to conduct. Their main weakness is the lack of randomisation, which means that selection

\begin{tabular}{|c|c|c|c|c|c|c|c|}
\hline & Country & $\begin{array}{l}\text { Entry criteria: } \\
\text { duration of LAl } \\
\text { treatment }\end{array}$ & $\begin{array}{l}\text { Mean duration } \\
\text { of LAI } \\
\text { treatment }\end{array}$ & $\begin{array}{l}\text { LAI } \\
\text { (no. of } \\
\text { participants) }\end{array}$ & $\begin{array}{l}\text { Analysis of } \\
\text { index } \\
\text { admission }\end{array}$ & $\begin{array}{l}\text { Total in-patient stay } \\
\text { (previous treatment } \\
\text { v. LAI), days }\end{array}$ & $\begin{array}{l}\text { Total no. of } \\
\text { admissions (previous- } \\
\text { treatment } v \text {. LAl) }\end{array}$ \\
\hline $\begin{array}{l}\text { Denham \& } \\
\text { Adamson } \\
(1971)^{25}\end{array}$ & UK & $\begin{array}{l}\text { More than } \\
1 \text { year }\end{array}$ & 24.8 months & $\begin{array}{l}\text { Fluphenazine } \\
\text { decanoate or } \\
\text { enanthate }(n=103)\end{array}$ & Excluded & $\begin{array}{l}8713 \text { v. } 1335 \\
\text { ( } P \text { not given) }\end{array}$ & $\begin{array}{l}191 \text { v. } 50 \\
\left(P<0.005^{\mathrm{a}}\right)\end{array}$ \\
\hline $\begin{array}{l}\text { Gottfries \& } \\
\text { Green }(1974)^{26}\end{array}$ & Sweden & $\begin{array}{l}\text { No minimum } \\
\text { treatment } \\
\text { period }\end{array}$ & $\begin{array}{l}\text { Not stated (most } \\
\text { treated for } 2-4 \\
\text { years) }\end{array}$ & $\begin{array}{l}\text { Flupentixol } \\
\text { decanoate }(n=58)\end{array}$ & Not stated & $\begin{array}{l}12562 \text { v. } 2981^{a} \\
\left(P<0.005^{a}\right)\end{array}$ & $\begin{array}{l}103 \text { v. } 37 \\
(P<0.005)\end{array}$ \\
\hline Morritt $(1974)^{27}$ & UK & 1 year & 12 months & $\begin{array}{l}\text { Fluphenazine } \\
\text { decanoate }(n=33)\end{array}$ & Not stated & $\begin{array}{l}2379 \text { v. } 801 \\
\left(P<0.005^{a}\right)\end{array}$ & $\begin{array}{l}60 \text { v. } 17 \\
\left(P<0.005^{\mathrm{a}}\right)\end{array}$ \\
\hline $\begin{array}{l}\text { Johnson } \\
(1975)^{28}\end{array}$ & UK & $>1$ year & 15 months & $\begin{array}{l}\text { Fluphenazine } \\
\text { decanoate }(n=140)\end{array}$ & Excluded & $\begin{array}{l}56 \% \text { reduction }{ }^{b} \\
\text { ( } P \text { not given) }\end{array}$ & $\begin{array}{l}38 \% \text { reduction }{ }^{b} \\
\text { ( } P \text { not given) }\end{array}$ \\
\hline $\begin{array}{l}\text { Lindholm } \\
(1975)^{29}\end{array}$ & Sweden & $>1$ year & 28.8 months $^{a}$ & $\begin{array}{l}\text { Perphenazine } \\
\text { enanthate }(n=24)\end{array}$ & Excluded & $\begin{array}{l}6607 \text { v. } 1151^{a} \\
\left(P<0.005^{a}\right)\end{array}$ & $\begin{array}{l}76 \text { v. } 34 \\
(P<0.05)\end{array}$ \\
\hline $\begin{array}{l}\text { Marriott \& } \\
\text { Hiep }(1976)^{30}\end{array}$ & Australia & $>1$ year & 22.7 months & $\begin{array}{l}\text { Fluphenazine } \\
\text { decanoate } \\
(n=131)\end{array}$ & $\begin{array}{l}\text { Split by } \\
\text { first dose }\end{array}$ & $\begin{array}{l}12434 \text { v. } 5619 \\
\left(P<0.005^{a}\right)\end{array}$ & Not assessed \\
\hline $\begin{array}{l}\text { Polonowita \& } \\
\text { James }(1976)^{31}\end{array}$ & New Zealand & $\begin{array}{l}\text { No minimum } \\
\text { period of treat- } \\
\text { ment required }\end{array}$ & 13.4 months & $\begin{array}{l}\text { Fluphenazine } \\
\text { decanoate }(n=35)\end{array}$ & $\begin{array}{l}\text { Split by first } \\
\text { dose }\end{array}$ & $\begin{array}{l}1463 \text { v. } 327 \\
(P<0.005)\end{array}$ & $\begin{array}{l}60 \text { v. } 22 \\
(P<0.005)\end{array}$ \\
\hline $\begin{array}{l}\text { Devito et al } \\
(1978)^{32, c}\end{array}$ & US & $\begin{array}{l}\text { Adherent for } \\
>3 \text { consecutive } \\
\text { months }\end{array}$ & Not stated & $\begin{array}{l}\text { Fluphenazine } \\
\text { decanoate }(n=61)\end{array}$ & Not stated & $\begin{array}{l}3329 \text { v. } 314^{a} \\
(P<0.05)\end{array}$ & $\begin{array}{l}93 \text { v. } 33 \\
(P<0.05)\end{array}$ \\
\hline $\begin{array}{l}\text { Freeman } \\
(1980)^{33}\end{array}$ & UK & $>1$ year & $\begin{array}{l}\text { Not stated } \\
\text { (12.5 years } \\
\text { follow-up) }\end{array}$ & $\begin{array}{l}\text { Not stated } \\
(n=143)\end{array}$ & Excluded & $\begin{array}{l}19510 \text { v. } 4376 \\
\text { ( } P \text { not given) }\end{array}$ & Not assessed \\
\hline $\begin{array}{l}\text { Tan et al } \\
(1981)^{34}\end{array}$ & Singapore & 2 years & 24 months & $\begin{array}{l}\text { Fluphenazine } \\
\text { decanoate }(n=127)\end{array}$ & Not stated & $\begin{array}{l}5264 \text { v. } 2533 \\
\text { ( } P \text { not given) }\end{array}$ & $\begin{array}{l}175 \text { v. } 140 \\
\text { ( } P \text { not given) }\end{array}$ \\
\hline $\begin{array}{l}\text { Tegeler \& } \\
\text { Lehmann } \\
(1981)^{35}\end{array}$ & Germany & $>1$ year & 62.4 months & Various $^{d}(n=76)$ & Excluded & $\begin{array}{l}18620 \text { v. } 3192 \\
(P<0.005)\end{array}$ & $\begin{array}{l}198 \text { V. } 68^{a} \\
(P<0.005)\end{array}$ \\
\hline Total $^{\mathrm{e}}$ & & & $\begin{array}{l}25.4 \text { months } \\
(n=669)\end{array}$ & Various & & $\begin{array}{l}90881 \text { v. } 22629(n=791) \\
\text { Per patient: } 114.9 \text { v. } 28.6\end{array}$ & $\begin{array}{l}956 \text { v. } 401(n=517) \\
\text { Per patient: } 1.8 \text { v. } 0.8\end{array}$ \\
\hline \multicolumn{8}{|c|}{$\begin{array}{l}\text { LAl, long-acting injection. } \\
\text { a. Denotes } P \text {-values or approximate figures we have extrapolated from the original published data. } \\
\text { b. Absolute figures not available. } \\
\text { C. In addition to the mirror-image analysis, the LAl group in Devito et al was compared with a separate oral cohort (see Table 3). } \\
\text { d. Includes penfluridol, fluphenazine decanoate, fluspirilene and flupentixol decanoate. } \\
\text { e. Total values based on available data in each column, e.g. mean LAl treatment duration is based on } 8 \text { studies, total in-patient stay based on } 10 \text { studies, etc. } \\
P \text {-values were stratified into the following groups: } P<0.05 \text { and } P<0.005 \text {. }\end{array}$} \\
\hline
\end{tabular}




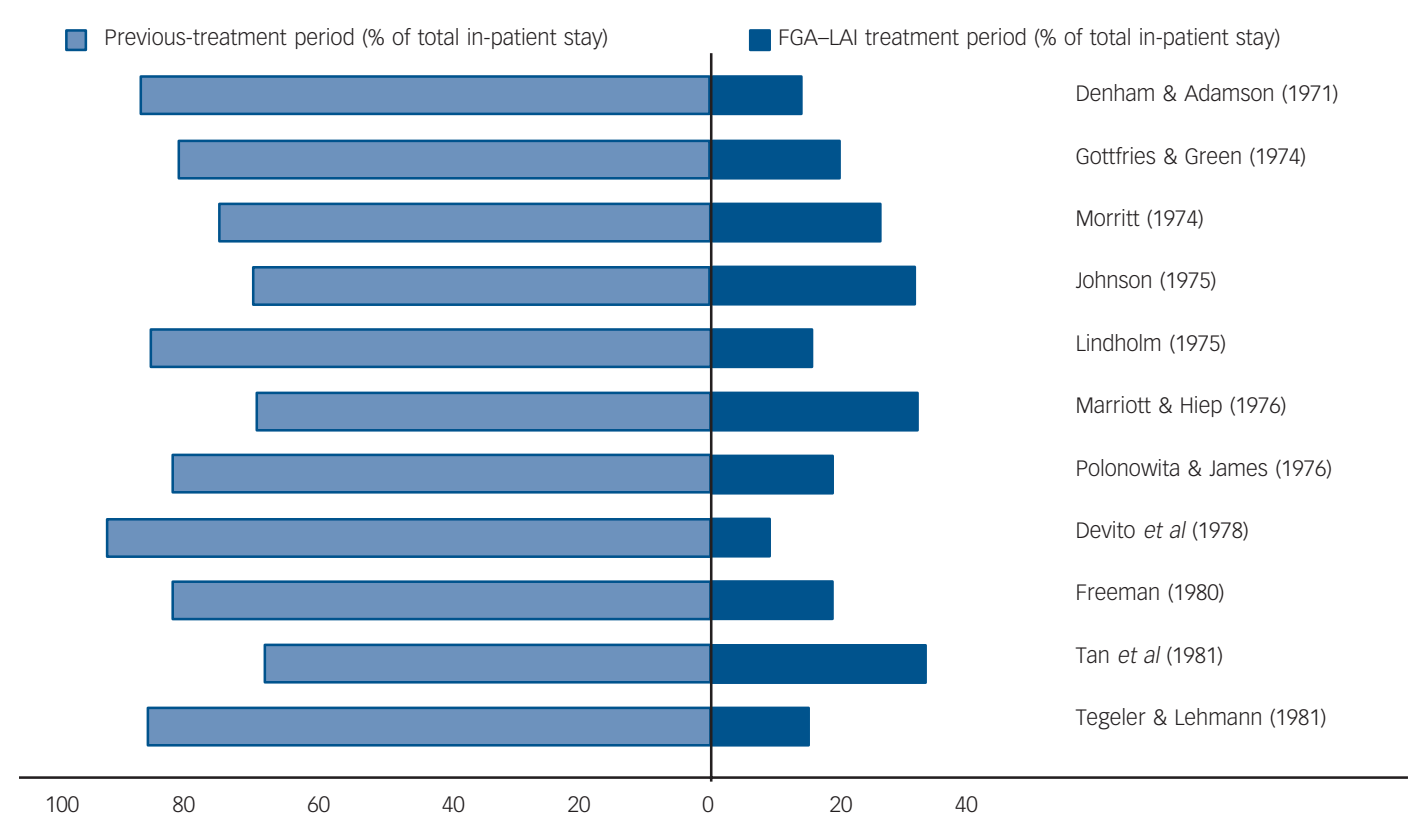

Fig. 4 Distribution (\%) of total in-patient stay between previous treatment and first-generation antipsychotic long-acting injection (FGA-LAl ) treatment periods for each of 11 mirror-image studies. ${ }^{25-35}$ Each horizontal bar is equivalent to $100 \%$.

bias and not allocated treatment may account for outcome. This is a particular problem when LAIs are compared with oral antipsychotics, as the individual characteristics of patients prescribed these two treatments often differ. Shi et al used data from the US-SCAP study to compare the characteristics of patients starting an FGA-LAI with those starting an SGA-oral or FGA-oral. ${ }^{2}$ Independent factors that predicted use of an LAI over oral medication included more severe psychotic symptoms, a higher rate of psychiatric hospitalisation in the previous year, a higher rate of current substance misuse, and a higher likelihood of being African American and having a history of arrest. Selection bias means that patients treated with an LAI would be expected to have a worse outcome than those treated with oral medication even if treatments were equally effective. Observational studies usually employ statistical techniques to correct for baseline variables, for example multivariate analysis and propensity scoring, but these may not adequately adjust for the selection bias if unknown or unmeasured variables affect outcome.
The two prospective studies in which FGA-LAI was superior to oral medication used an FGA-oral comparator, ${ }^{19,20}$ whereas the two studies that showed a worse outcome for FGA-LAIs selected an SGA-oral comparator (Table1). ${ }^{21,23}$ The conflicting results may be because selection bias is greater when comparing between formulation (oral or LAI) and simultaneously between class (FGA or SGA). Consistent with this, outcomes in the SOHO study appeared similar for the FGA-LAI and FGA-oral cohorts ( $P$-values not provided). ${ }^{21}$ In the study by Conley et al outcomes did not differ significantly between fluphenazine decanoate and SGA-orals, whereas haloperidol decanoate was inferior to SGAorals. ${ }^{23}$ This may reflect the poorer tolerability of haloperidol decanoate compared with fluphenazine decanoate.

\section{Mirror-image studies}

We identified 11 mirror-image studies (see Table 2) in contrast to the 6 mirror-image studies identified in an earlier review of

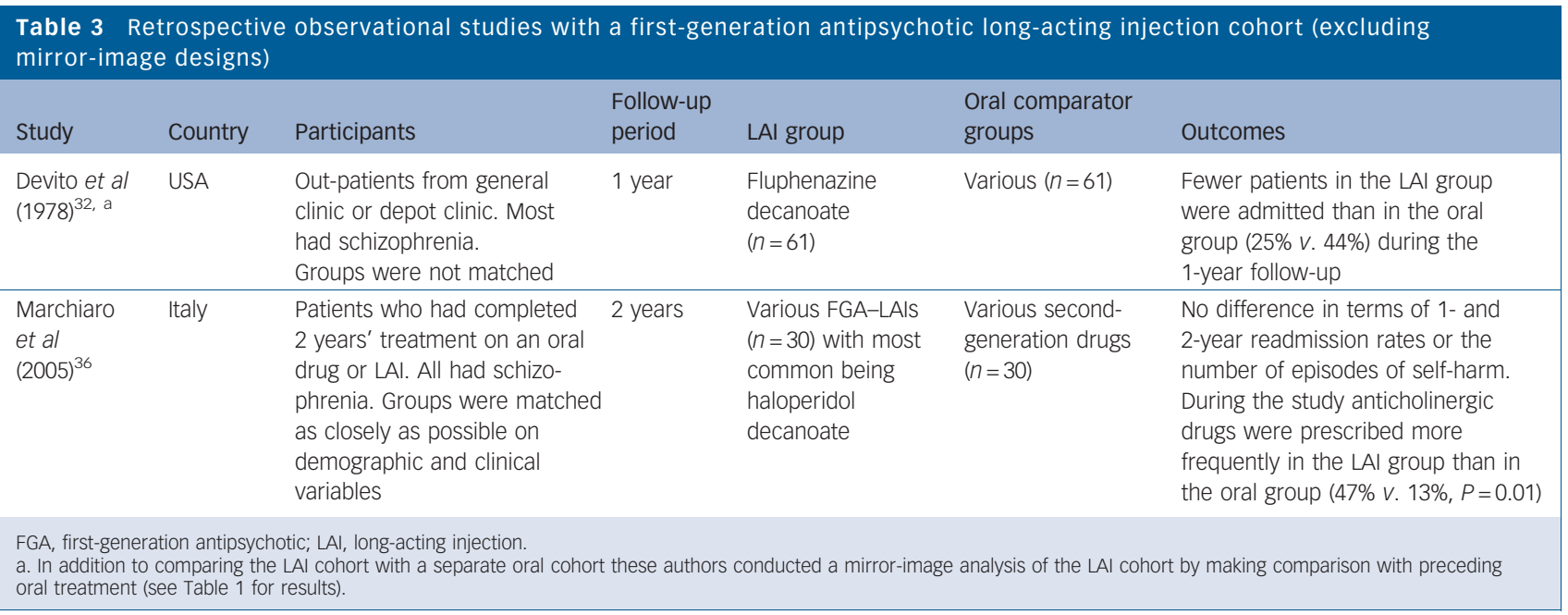


FGA-LAIs by Davis et al. ${ }^{40}$ Although these studies consistently showed reduced in-patient care after switching to an LAI, methodological issues mean that this cannot be accepted as categorical evidence that LAIs are superior. It is well recognised that mirror-image studies can be confounded by independent events that occur during the study, for example a reduction in hospital beds or the introduction of improved community support. ${ }^{40}$ In addition, admission length can be influenced by non-clinical factors such as the availability of discharge accommodation. Mirror-image designs have other methodological weaknesses that have been largely neglected in the literature. These include an inherent bias towards improvement, the issue of how 'index admissions' are analysed for those who begin LAI treatment as in-patients, and selection of LAI responders. These issues are discussed further in this section.

Mirror-image studies have an inherent design bias, namely that the initial treatment (in this case oral medication) ends with treatment failure, otherwise the second medication (in this case an LAI) would not be commenced. If the reason for switching is lack of efficacy rather than intolerability, then subsequent improvement in terms of admissions or bed-days could represent natural remission (i.e. a regression to the mean effect) rather than the superiority of a new medication. Hospital admission for people with schizophrenia is especially liable to regression to the mean because it represents extreme decompensation in a chronic fluctuating illness.

Another methodological issue, for those who start LAI treatment as an in-patient, is how the index admission (i.e. the admission during which LAI is started) is analysed. This is important, as a high proportion of LAI patients begin treatment as in-patients. As the index admission results from failure of the preceding oral medication, the initial assumption is to attribute it to prior treatment. However, the duration of the index admission may be lengthened when switching to an LAI as opposed to an oral antipsychotic, owing to the need for a test dose with FGA-LAIs and the longer time required to achieve a therapeutic plasma level. Three ways of analysing the index admission exist: exclude it from analysis (this may introduce a bias against the LAI); allocate it totally to prior treatment (this may introduce a bias in favour of the LAI); or divide it between the two treatments according to the start date of the LAI (a compromise between the two previous methods of analysis). There is no right or wrong way to analyse the index admission and different researchers have taken different views. Of the 11 mirror-image studies we reviewed, 5 excluded the index admission, 2 divided it between preceding treatment and LAI, and the remaining 4 studies did not specify the approach adopted. We recommend that future mirror-image studies are explicit about how the index admission is analysed.

Some mirror-image studies select LAI responders by restricting analysis to those who have completed a minimum length of LAI treatment rather than considering all those who started an LAI during a defined period. Seven of the 11 studies we identified assessed those who had completed at least 12 months of LAI treatment, and a further study included only those who had completed 2 years of LAI treatment (see Table 2). ${ }^{34}$

\section{Other retrospective observational studies}

Of the two retrospective studies with a separate oral comparator group, matching was attempted in one. ${ }^{36}$ However, this study was limited by the patients being highly selected, unrepresentative and biased towards an adherent group. Entry criteria included completing 2 years of treatment on the same drug and no Axis I diagnosis other than schizophrenia. This meant that patients with comorbid substance misuse - a predictor of poor adherence ${ }^{37,38}$ and rehospitalisation ${ }^{41}$ - were excluded. These factors may contribute to the finding of comparable readmission rates for oral medication and LAI. ${ }^{36}$ The other study in this category found a lower readmission rate for patients on LAI compared with those on oral medication. ${ }^{32}$ However, the small sample $(n=61$ in each arm) and lack of randomisation mean that the result needs to be viewed with caution.

\section{Tolerability}

There was a scarcity of reported tolerability data. Most related to extrapyramidal symptoms and tardive dyskinesia, but only the prevalence rate for tardive dyskinesia in the meta-analysis by Adams et al was based on the use of objective rating scales. ${ }^{12}$ Two studies used the prescription of anticholinergic drugs as a marker for extrapyramidal symptoms, ${ }^{12,36}$ and in the SOHO study the presence of extrapyramidal symptoms and tardive dyskinesia was based on clinical judgement. ${ }^{22}$ Three period prevalence rates (maximum duration of 3 years) for extrapyramidal symptoms in patients on FGA-LAI were available: $42.8 \%$ in the SOHO prospective study, ${ }^{21,22} 47.0 \%$ in a retrospective case-note study, ${ }^{36}$ and $69.5 \%$ in a meta-analysis. ${ }^{12}$ Two period prevalence rates (maximum duration 2 years) were available for tardive dyskinesia: $9.0 \%$ in a meta-analysis and $12.9 \%$ in the SOHO study. ${ }^{12,22}$ Despite the methodological limitations, these prevalence rates are high, possibly reflecting a high use of haloperidol LAI in two studies. ${ }^{22,36}$ The only study to make a statistical comparison between rates of extrapyramidal symptoms and tardive dyskinesia in patients prescribed FGA-LAI and FGA-oral drugs was that by Adams et al, and the rates were comparable. ${ }^{12}$

Two observational studies, the SOHO study and that by Marchiaro et al, reported higher rates of extrapyramidal symptoms and tardive dyskinesia in a cohort prescribed various FGA-LAIs than in patients prescribed SGA-oral drugs. ${ }^{22,36}$ This suggests that SGAs may be associated with a lower incidence of extrapyramidal symptoms and tardive dyskinesia than some FGA-LAIs (haloperidol LAI was the predominant LAI in the study by Marchiaro et $a{ }^{36}$ and the breakdown of LAIs in the SOHO study is not given.) $)^{22}$ Future studies should compare the extrapyramidal symptoms liability of specific drugs rather than make generalisations about SGAs and FGAs as the risk varies between different drugs within both respective groups. ${ }^{42} \mathrm{~A}$ recent meta-analysis showed that all SGAs were associated with much fewer extrapyramidal symptoms than haloperidol, but the advantage was either absent or much less apparent in a comparison with low-potency FGAs. ${ }^{43}$ In the Clinical Antipsychotic Trials of Intervention Effectiveness (CATIE) and Cost Utility of the Latest Antipsychotics in Schizophrenia Study (CUtlASS) trials, ${ }^{44,45}$ the prevalence of extrapyramidal symptoms did not differ between SGAs and the FGA comparator - perphenazine in CATIE, ${ }^{44}$ and various FGAs (but predominantly sulpiride) in CUtlASS. ${ }^{45}$

\section{Conclusions and future research}

Randomised controlled trials and observational studies have different strengths and weaknesses, and reviewing them alongside each other as in this systematic review provides the most comprehensive assessment. Overall we found variable and inconclusive results. The four study designs we considered (RCTs, prospective observational studies, mirror-image studies and other retrospective studies) all showed some evidence of better outcome with FGA-LAIs than with oral antipsychotic medication, but some studies showed the converse or no difference between the two groups. The variability in results may partly reflect methodological 
issues. Selective recruitment into RCTs and lack of randomisation in observational studies can bias against LAIs, whereas regression to the mean in mirror-image studies can favour LAIs. Overall the results suggest that FGA-LAIs may have a benefit over oral medication but this is far from conclusive.

Given these inconclusive results, a pragmatic RCT comparing an oral antipsychotic drug and an FGA-LAI would be of value. The primary outcome should be relapse (operationally defined) and the trial should be of sufficient duration to assess this. Secondary outcome measures could include symptomatic improvement, a range of adverse effects (including extrapyramidal symptoms, tardive dyskinesia, weight gain and metabolic parameters), user satisfaction and cost-effectiveness. It would be important to recruit patients at risk of relapse in whom antipsychotic adherence has been poor, because this is the primary group for whom clinicians consider using LAIs. Exclusion criteria should be minimal. Such a trial is relevant as FGA-LAIs remain widely prescribed and recent pragmatic RCTs, including CATIE and CUtLASS, ${ }^{44,45}$ have shown similar outcomes for oral FGAs and oral SGAs other than clozapine.

There are accumulating data from long-term RCTs of SGA-LAIs $v$. oral medication. ${ }^{46-49}$ This allows for an updated meta-analysis that compares both FGA-LAIs and SGA-LAIs with oral antipsychotics. Future research could also compare an FGA-LAI with an SGA-LAI; in theory a single trial could compare an FGA-LAI, an SGA-LAI and an oral antipsychotic.

The high prevalence rates of extrapyramidal symptoms (43$70 \%)$ and tardive dyskinesia (9-13\%) reported over periods up to 3 years with FGA-LAIs emphasises the importance of screening patients regularly for extrapyramidal symptoms, although in practice this is often neglected. ${ }^{50,51}$ Screening should cover a full range of potential adverse effects, including weight gain and metabolic abnormalities, and ideally occur in a systematic manner using a practical but valid scale. ${ }^{52}$

Current guidelines recommend that long-acting injections be considered for patients with schizophrenia who adhere poorly to oral medication regimens and for patients who express a preference for this treatment. ${ }^{53-57}$ Despite the inconclusive results of our review we support these recommendations. Even if LAIs do not reduce relapse rates beyond those seen with oral medication, they prevent covert non-adherence, which is beneficial. ${ }^{58}$ The decision to use an LAI should be made on an individual patient basis, usually as a joint decision by the clinician and patient. Long-acting injections can only lead to improved outcomes if a patient is committed to this form of treatment.

\section{Acknowledgement}

We thank Andrew Bradley, Eli Lilly, for creating Fig. 2 from data in the corresponding paper

Peter M. Haddad, MRCPsych, MD, Greater Manchester West Mental Health NHS Foundation Trust, Salford, and University of Manchester; Mark Taylor, BSC(Hons), FRCPsych, FRANZCP, Ballenden House, Edinburgh and University of Glasgow; Omair
FRoundation Trust, S. Niaz, MBChB, MRCPsych, Sheffield Health and Social Care NHS Foundation Trust, S. Niaz, MBChB
Sheffield, UK

Correspondence: Dr P. M. Haddad, Cromwell House, Cromwell Road, Eccles, Salford M30 0GT, UK. Email: peter.haddad@gmw.nhs.uk

\section{References}

1 Johnson DAW. Historical perspective on antipsychotic long-acting injections Br J Psychiatry 2009; 195 (suppl 52): s7-12.

2 Shi L, Ascher-Svanum H, Zhu B, Faries D, Montgomery W, Marder SR. Characteristics and use patterns of patients taking first-generation depot antipsychotics or oral antipsychotics for schizophrenia. Psychiatr Serv 2007; 58: $482-8$.
3 Paton C, Lelliott P, Harrington M, Okocha C, Sensky T, Duffett R. Patterns of antipsychotic and anticholinergic prescribing for hospital inpatients. J Psychopharmacol 2003, 17; 223-9.

4 Barnes TRE, Shingleton-Smith A, Paton C. Antipsychotic long-acting injections: prescribing practice in the UK. Br J Psychiatry 2009; 195 (suppl 52): s37-42.

5 Leucht S, Barnes TR, Kissling W, Engel RR, Correll C, Kane JM. Relapse prevention in schizophrenia with new-generation antipsychotics: a systematic review. Am J Psychiatry 2003; 160: 1209-22.

6 Carpenter WT, Hanlon TE, Heinrichs DW, Summerfelt AT, Kirkpatrick B Levine J, et al. Continuous versus targeted medication in schizophrenic outpatients: outcome results. Am J Psychiatry 1990; 147: 1138-48.

7 Herz MI, Glazer WM, Mostert MA, Sheard MA, Szymanski HV, Hafez H, et al. Intermittent vs maintenance medication in schizophrenia. Two-year results. Arch Gen Psychiatry 1991; 48: 333-9.

8 Cramer JA, Rosenheck R. Compliance with medication regimens for mental and physical disorders. Psychiatr Serv 1998; 49: 196-201.

9 Robinson D, Woerner MG, Alvir JM, Bilder R, Goldman R, Geisler S, et al Predictors of relapse following response from a first episode of schizophrenia or schizoaffective disorder. Arch Gen Psychiatry 1999; 56: 241-7.

10 Law MR, Soumerai SB, Ross-Degnan D, Adams AS. A longitudinal study of medication nonadherence and hospitalization risk in schizophrenia. J Clin Psychiatry 2008; 69: 47-53.

11 Bond DJ, Pratoomsri W, Yatham LN. Depot antipsychotic medications in bipolar disorder: a review of the literature. Acta Psychiatr Scand Suppl 2007; 434: 3-16.

12 Adams CE, Fenton MKP, Quraishi S, David AS. Systematic meta-review of depot antipsychotic drugs for people with schizophrenia. Br J Psychiatry 2001; 179: 290-9.

13 Adams CE, David A, Quraishi SN. Depot bromperidol decanoate for schizophrenia. Cochrane Database Syst Rev 2004; (3): CD001719.

14 David A, Adams CE, Eisenbruch M, Quraishi S, Rathbone J. Depot fluphenazine decanoate and enanthate for schizophrenia. Cochrane Database Syst Rev 2004; (2): CD000307.

15 Abhijnhan A, Adams CE, David A, Ozbilen M. Depot fluspirilene for schizophrenia. Cochrane Database Syst Rev 2007; (1): CD001718.

16 David A, Quraishi S, Rathbone J. Depot perphenazine decanoate and enanthate for schizophrenia. Cochrane Database Syst Rev 2005; (3): CD001717.

17 Dinesh M, David A, Quraishi SN. Depot pipotiazine palmitate and undecylenate for schizophrenia. Cochrane Database Syst Rev 2004; (3): CD001720.

18 Arango C, Bombin I, Gonzalez-Salvador T, Garcia-Cabeza I, Bobes J. Randomised clinical trial comparing oral versus depot formulations of zuclopenthixol in patients with schizophrenia and previous violence. Eur Psychiatry 2006; 21: 34-40.

19 Tiihonen J, Walhbeck K, Lönnqvist J, Klaukka T, Ioannidis JP, Volavka J, et al. Effectiveness of antipsychotic treatments in a nationwide cohort of patients in community care after first hospitalisation due to schizophrenia and schizoaffective disorder: observational follow-up study. BMJ 2006; 333 224-7.

20 Zhu B, Ascher-Svanum H, Shi L, Faries D, Montgomery W, Marder SR. Time to discontinuation of depot and oral first-generation antipsychotics in the usual care of schizophrenia. Psychiatr Serv 2008; 59: 315-7.

21 Haro JM, Novick D, Suarez D, Alonso J, Lépine JP, Ratcliffe M. Remission and relapse in the outpatient care of schizophrenia: three-year results from the Schizophrenia Outpatient Health Outcomes study. J Clin Psychopharmacol 2006; 26: 571-8.

22 Haro JM, Suarez D, Novick D, Brown J, Usall J, Naber D. Three-year antipsychotic effectiveness in the outpatient care of schizophrenia: observational versus randomized studies results. Eur Neuropsychopharmacol 2007; 17: 235-44.

23 Conley RR, Kelly DL, Love RC, McMahon RP. Rehospitalization risk with second-generation and depot antipsychotics. Ann Clin Psychiatry 2003; 15 23-31.

24 Haddad PM, Niaz O. What works in schizophrenia: depot preparations may improve outcomes. BMJ 2006; 333: 353.

25 Denham J, Adamson L. The contribution of fluphenazine enanthate and decanoate in the prevention of readmission of schizophrenic patients. Acta Psychiatr Scand 1971; 47: 420-30.

26 Gottfries CG, Green L. Flupenthixol decanoate - in treatment of out-patients. Acta Psychiatr Scand Suppl 1974; 255: 15-24.

27 Morritt C. Long-acting phenothiazines and schizophrenia. Nurs Mirror Midwives J 1974; 138: 57-9. 
28 Johnson DAW. Observations on the dose regime of fluphenazine decanoate in maintenance therapy of schizophrenia. Br J Psychiatry 1975; 126: 457-61.

29 Lindholm $\mathrm{H}$. The consumption of inpatient psychiatric resources prior to and during treatment with a depot neuroleptic, perphenazine enanthate. A mirror study. Nord Psykiatr Tidsskr 1975; 29: 513-20.

30 Marriott $P$, Hiep A. A mirror image out-patient study at a depot phenothiazine clinic. Aust N Z J Psychiatry 1976; 10: 163-7.

31 Polonowita A, James NM. Fluphenazine decanoate maintenance in schizophrenia: a retrospective study. N Z Med J 1976; 83: 316-8.

32 Devito RA, Brink L, Sloan C, Jolliff F. Fluphenazine decanoate vs oral antipsychotics: a comparison of their effectiveness in the treatment of schizophrenia as measured by a reduction in hospital readmissions. J Clin Psychiatry 1978; 39: 26-34.

33 Freeman $\mathrm{H}$. Twelve years' experience with the total use of depot neuroleptics in a defined population. Adv Biochem Psychopharmacol 1980; 24: 559-64.

34 Tan CT, Ong TC, Chee KT. The use of fluphenazine decanoate (Modecate) depot therapy in outpatient schizophrenics - a retrospective study. Singapore Med J 1981; 22: 214-8.

35 Tegeler J, Lehmann E. A follow-up study of schizophrenic outpatients treated with depot-neuroleptics. Prog Neuropsychopharmacol 1981; 5: 79-90.

36 Marchiaro L, Rocca P, LeNoci F, Longo P, Montemagni C, Rigazzi C, et al. Naturalistic, retrospective comparison between second-generation antipsychotics and depot neuroleptics in patients affected by schizophrenia. J Clin Psychiatry 2005; 66: 1423-31.

37 Cooper D, Moisan J, Grégoire JP. Adherence to atypical antipsychotic treatment among newly treated patients: a population-based study in schizophrenia. J Clin Psychiatry 2007; 68: 818-25.

38 Hudson TJ, Owen RR, Thrush CR, Han X, Pyne JM, Thapa P, et al. A pilot study of barriers to medication adherence in schizophrenia. J Clin Psychiatry 2004; 65: 211-6.

39 Chouinard G, Annable L, Steinberg S. A controlled clinical trial of fluspirilene, a long-acting injectable neuroleptic, in schizophrenic patients with acute exacerbation. J Clin Psychopharmacol 1986; 6: 21-6.

40 Davis JM, Matalon L, Watanabe MD, Blake L. Depot antipsychotic drugs. Place in therapy. Drugs 1994; 47: 741-73.

41 Olfson M, Mechanic D, Boyer CA, Hansell S, Walkup J, Weiden PJ. Assessing clinical predictions of early rehospitalization in schizophrenia. J Nerv Ment Dis 1999; 187: 721-9.

42 Haddad PM, Sharma SG. Adverse effects of atypical antipsychotics: differential risk and clinical implications. CNS Drugs 2007; 21: 911-36.

43 Leucht S, Corves C, Arbter D, Engel RR, Li C, Davis JM. Second-generation versus first-generation antipsychotic drugs for schizophrenia: a meta-analysis. Lancet 2009; 373: 31-41.

44 Lieberman JA, Stroup TS, McEvoy JP, Swartz MS, Rosenheck RA, Perkins DO, et al. Effectiveness of antipsychotic drugs in patients with chronic schizophrenia. N Engl J Med 2005; 353: 1209-23.
45 Jones PB, Barnes TR, Davies L, Dunn G, Lloyd H, Hayhurst KP, et al. Randomized controlled trial of the effect on quality of life of second- vs firstgeneration antipsychotic drugs in schizophrenia: Cost Utility of the Latest Antipsychotic Drugs in Schizophrenia Study (CUtLASS 1). Arch Gen Psychiatry 2006; 63: 1079-87.

46 Keks NA, Ingham M, Khan A, Karcher K. Long-acting injectable risperidone $v$. olanzapine tablets for schizophrenia or schizoaffective disorder. Randomised, controlled, open-label study. Br J Psychiatry 2007; 191: 131-9.

47 Medori R, Wapenaar R, de Arce R, Rouillon F, Gaebel W, Cordes J, et al. Relapse prevention and effectiveness of risperidone long-acting injection (RLAI) versus quetiapine or aripiprazole. In American Psychiatric Association 2008 Annual Meeting: New Research Abstracts: 203 (NR4-094). APA, 2008 (http://www.psych.org/am2008newresearch).

48 Eli Lilly. Comparison of Intramuscular Olanzapine Depot to Oral Olanzapine and Low-Dose Depot in Patients With Schizophrenia. Identifier NCT00088491. ClinicalTrials.gov, 2007 (http://clinicaltrials.gov/ct2/show/nct00088491).

49 Citrome L. Olanzapine pamoate: a stick in time? A review of the efficacy and safety profile of a new depot formulation of a second-generation antipsychotic. Int J Clin Pract 2009; 63: 140-50.

50 Mitra S, Haddad P. Documentation of extrapyramidal symptoms. Psychiatr Bull 2007; 31: 76-7.

51 Prescribing Observatory for Mental Health. Topic 6 Baseline Report. Assessment of Side-Effects of Depot Antipsychotics. (CRTU064). POMH, 2008.

52 Waddell L, Taylor M. A new self-rating scale for detecting atypical or secondgeneration antipsychotic side effects. J Psychopharmacol 2008; 22: 238-43.

53 Kane JM, Leucht S, Carpenter D, Docherty JP. Expert Consensus Panel for Optimizing Pharmacologic Treatment of Psychotic Disorders. The expert consensus guideline series. Optimizing pharmacologic treatment of psychotic disorders. Introduction: methods, commentary, and summary. J Clin Psychiatry 2003; 64 (suppl 12): 5-19.

54 Kane JM, Aguglia E, Altamura AC, Ayuso Gutierrez JL, Brunello N, Fleischhacker WW, et al. Guidelines for depot antipsychotic treatment in schizophrenia. European Neuropsychopharmacology Consensus Conference in Siena, Italy. Eur Neuropsychopharmacol 1998; 8: 55-66.

55 Lehman AF, Kreyenbuhl J, Buchanan RW, Dickerson FB, Dixon LB, Goldberg R, et al. The Schizophrenia Patient Outcomes Research Team (PORT): updated treatment recommendations 2003. Schizophr Bull 2004: 30: 193-217.

56 Miller AL, Hall CS, Buchanan RW, Buckley PF, Chiles JA, Conley RR, et al. The Texas Medication Algorithm Project antipsychotic algorithm for schizophrenia: 2003 update. J Clin Psychiatry 2004; 500-8.

57 National Institute for Health and Clinical Excellence. Core Interventions in the Treatment and Management of Schizophrenia in Primary and Secondary Care. NICE, 2002

58 Barnes TR, Curson DA. Long-term depot antipsychotics. A risk-benefit assessment. Drug Saf 1994; 10: 464-79. 